\title{
FIVE SECOND HELIUM \\ NEUTRAL BEAM INJECTION USING ARGON-FROST CRYOPUMPING TECHNIQUES
}

by

J.C. PHILLIPS, D.H. KELLMAN, R. HONG,

J. KIM, and G.M. LAUGHON

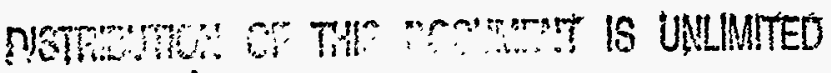

p

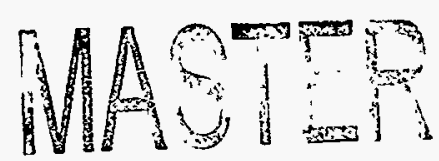

OCTOBER 1995 


\section{DISCLAIMER}

This report was prepared as an account of work sponsored by an agency of the United States Government. Neither the United States Government nor any agency thereof, nor any of their employees, makes any warranty, express or implied, or assumes any legal liability or responsibility for the accuracy, completeness, or usefulness of any information, apparatus, product, or process disclosed, or represents that its use would not infringe privately owned rights. Reference herein to any specific commercial product, process, or service by trade name, trademark, manufacturer, or otherwise, does not necessarily constitute or imply its endorsement, recommendation, or favoring by the United States Government or any agency thereof. The views and opinions of authors expressed herein do not necessarily state or reflect those of the United States Government or any agency thereof. 


\title{
FIVE SECOND HELIUM NEUTRAL BEAM INJECTION USING ARGON-FROST CRYOPUMPING TECHNIQUES
}

\author{
by \\ J.C. PHILLIPS, D.H. KELLMAN, R. HONG, \\ J. KIM, and G.M. LAUGHON
}

This is a preprint of a paper presented at the 16th IEEE/NPSS Symposium on Fusion Engineering, September 30-October 5, 1995, Champaign, Illinois, and to be printed in the Proceedings.

\author{
Work supported by \\ U.S. Department of Energy \\ Contract DE-AC03-89ER51114
}

GENERAL ATOMICS PROJECT 3466 OCTOBER 1995 


\section{DISCLAIMER}

Portions of this document may be tliegible in electronicimage products. Images are produced from the best available original document. 


\title{
Five Second Helium Neutral Beam Injection Using Argon-Frost Cryopumping Techniques*
}

\author{
J.C. Phillips, D.H. Kellman, R. Hong, J. Kim, G.M. Laughon \\ General Atomics \\ P.O. Box 85608, San Diego, California 92186-9784
}

\section{ABSTRACT}

High power helium neutral beams for the heating of tokamak discharges can now be provided for $5 \mathrm{~s}$ by using argon cryopumping (of the helium gas) in the beamlines.

The DIII-D neutral beam system has routinely provided up to $20 \mathrm{MW}$ of deuterium neutral beam heating in support of experiments on the DIII-D tokamak. During normal operation each of the eight DIII-D neutral beams produces from 20-30 Torr $\ell / \mathrm{s}$ of deuterium gas for periods of up to $8 \mathrm{~s}$ per discharge. This gas is effectively pumped by the $4.3 \mathrm{~K}$ cryopanels present in each beamline, and only a small fraction is conducted into the DIII-D tokamak. Operation of neutral beams with helium has historically presented a problem in that pulse lengths have been limited to $500 \mathrm{~ms}$ due to reliance solely on volume pumping of the helium gas. Helium is not condensed on the cryopanels.

A system has now been installed to deposit a layer of argon frost on the DIII-D neutral beam cryopanels, between tokamak injection pulses. The layer serves to trap helium on the cryopanels providing sufficient pumping speed for $5 \mathrm{~s}$ helium beam extraction. The argon frosting hardware is now present on two of four DIII-D neutral beamlines, allowing injection of up to $6 \mathrm{MW}$ of helium neutral beams per discharge, with pulse lengths of up to $5 \mathrm{~s}$.

The argon frosting system is described, along with experimental results demonstrating its effectiveness as a method of economically extending the capabilities of cryogenic pumping panels to allow multi-second helium neutral beam injection.

\section{INTRODUCTION}

Helium neutral beam injection allows central fueling of the plasma with helium, as opposed to gas puffing which fuels the edge, and therefore provides a method to simulate the conditions in a fusion reactor, in which helium is generated in the plasma core via fusion reactions. (Core fueling is expected to be the primary mode of operation of devices such as ITER.)

During normal deuterium operation of the DIII-D neutral beams, the deuterium gas injected into both the ion source arc chamber and the neutralizer cell is pumped quickly and efficiently by two LHe panels located in the forward and rear spools of each beamline. Both panels employ a design whereby the LHe cooled surfaces are shielded by $\mathrm{LN}_{2}$ cooled surfaces. The forward LHe panel has a surface area of $6 \mathrm{~m}^{2}$, the rear $8 \mathrm{~m}^{2}$. Together these panels provide a pumping speed in excess of $1.4 \times 10^{6} \mathrm{l} / \mathrm{s}$ for deuterium [1].

In the past, operation of the DIII-D neutral beams using helium has been limited to short $(500 \mathrm{~ms})$ pulses, because helium gas is not pumped by the $4.3 \mathrm{~K}$ LHe panel surfaces. The pumping of the helium gas was constrained by the conductance of the foreline to the Roots blowers atop mechanical pumps some $25 \mathrm{~m}$ from the beamlines, resulting in actual pumping speeds for helium of only about $50 \mathrm{l} / \mathrm{s}$. Fast pumping, on the order of $2 \times 10^{5} \mathrm{l} / \mathrm{s}$ is required for operation of the accelerator.

In an effort to provide significantly longer helium neutral beam pulses and increased helium neutral energy to the DIII-D plasma, a program was undertaken to experiment with pumping this helium gas by means of argon-frost cryopumping techniques [2]. Helium atoms can be efficiently trapped between the large argon atoms condensed on the LHe panel surface. This method was tested in one beamline previously to determine the required argon-to-helium molecular ratio $(-50: 1)$ for efficient cryotrapping. While this pumping can be achieved with as little as a mono-layer of argon frost, experiments were done to attempt to optimize helium pumping with respect to the quantity of argon gas injected into the beamline between each neutral beam pulse. Previous work has shown that increasing the depth of the argon-frost layer does not increase helium pumping speed $[3,4]$, but in the case where the quantity of available argon frost is insufficient for the helium pumping required, beamline pressures rise rapidly Fig. 1, terminating the pulse and resulting in a long wait while the helium gas is pumped out by more traditional volume pumping delaying operations - a situation to be avoided.

Reliable operation of each beamline's two ion sources with simultaneous $5 \mathrm{~s}$ helium beam pulses has been repeatably demonstrated, given that a fresh argon frost layer was produced by injecting $2300 \mathrm{Torr} \cdot \ell$ of argon into the beamline between tokamak discharges.

In this paper we present pumping speed measurements, a description of the hardware involved, and a characterization of our ion source operation in helium.

\section{HELIUM CRYOTRAPPING CHARACTERISTICS}

Measurement of the helium pumping speed by the argon frost layer has been carried out in one of the four DIII-D neutral

\footnotetext{
*Work supported by the U.S. Department of Energy under Contract No. DE-AC03-89ER51114.
} 
given a constraint of less than one second at 30 Torr $\ell / s$ using volume pumping. The arc was established and beam extracted within $200 \mathrm{~ms}$, during a period when the arc was not yet fully stabilized and regulated. This led to somewhat erratic ion source operation. The argon cryo-frost pumping techniques described here have allowed a more generous period of time, on the order of $2500 \mathrm{~ms}$, for the arc to stabilize before extracting beam, resulting in far more reliable operation of the ion sources in helium.

\section{CRYOPANEL MANAGEMENT IN ARGON}

An interesting operational observation is made of the behaviour of the cryo-panels after having been coated with layers of argon frost. Under normal deuterium operation the LHe panels can easily be "regenerated" or warmed up. As soon as the panel temperature is raised a few degrees Kelvin, either intentionally or by accident, the deuterium gas trapped on the panel is evolved. However, when layers of argon frost have been trapped on the panels it becomes more difficult to raise their temperature, since the argon frost acts as an insulating layer. When the panel does warm up, the Argon is released gradually at temperatures in the $50 \mathrm{~K}$ range, much higher than the normal $4.3 \mathrm{~K}$ temperature of the panels. Thus regenerating the panels once frosted with argon takes a significant period of time, on the order of an hour. Further, once the argon frosted panels are regenerated after pumping significant quantities of helium gas, the time to pump the helium gas from the beamline, given the $60 \mathrm{l} / \mathrm{s}$ pumping speed noted previously, can also be long. The operating implications of these observations are two-fold, one beneficial in that it becomes more difficult for the LHe panel to go unstable on an accidental basis once the insulating argon frost layer is in place, the other being that much longer periods of time must be allowed for regenerating the argon frosted, helium loaded panels - on the order of two hours or more.

Work by M. Menon, et al. [3,5], has shown that loading the argon frosted panels with deuterium gas decreases the ability to pump helium gas, roughly exponentially with the quantity of deuterium pumped. In normal operation of DIII-D with neutral beam heating, the isolation valves between the beamlines and the tokamak are kept closed except for the duration of the plasma shot. The influx of deuterium gas into all of the beamlines is estimated at $5000 \mathrm{l} / \mathrm{s}$ for most standard plasma shots lasting 4 or $5 \mathrm{~s}$. This needs to be taken into account when determining the quantity of argon frost required to be deposited on the neutral beam cryopanels in support of helium pumping.

Since the bending magnets, and the neutralizer gas systems, are separate entities for each ion source, it is possible within a single beamline to operate one ion source in deuterium gas and one ion source in helium gas. While this mode of operation has not yet been attempted, it is predictable that the argon layer would have to be increased substantially, in order to accomplish this mode of operation.

\section{RESULTS}

Five second beam extraction, simultaneously from both ion sources located on a particular beamline, has been successfully demonstrated, using argon-frost cryopumping. Importantly, operational experience has been gained both with the behavior of the helium arc phase of beam extraction, and with the behavior of the cryopanels themselves when argon frosted and loaded with trapped helium. Given this experience we are in a position to set up for helium neutral beam operation on short notice and provide reliable helium beams in support of DIII-D plasma physics experiments.

The hardware and procedures outlined above have proved to be an economical program allowing a ten-fold increase in the pulse length of the DIII-D neutral beams operating in helium. In fact, the $5 \mathrm{~s}$ limit is not imposed by the argon-frost cryo pumping, but is rather the duration limit imposed on all DIII-D neutral beam pulses, in accordance with power supply design and specifications. There is no reason that this helium pumping scheme described here could not support longer pulse lengths.

\section{FUTURE PLANS}

Currently, the beamline argon gas puffing system as described is installed and available on only two of four beamlines, located at $150^{\circ}$ and $210^{\circ}$. Future plans call for similar installations on the $30^{\circ}$ and $330^{\circ}$ beamlines, allowing for a full $12 \mathrm{MW}$ of helium neutral beam injection. In addition, we hope to gain actual operating experience with running both deuterium and helium neutral beam within the same beamline.

\section{REFERENCES}

[1] A.R. Langhorn, J. Kim, et al., "Performance of Doublet III neutral beam injector cryopumping system," J. Vac. Sci. Technol. A 2, 1193, 1984.

[2] J. Hengevoss, and E.A. Trendelburg, "Continuous cryotrapping of hydrogen and helium by argon at $4.2 \mathrm{~K}$," Trans. of the 10 th National Symp. of the Am. Vac. Soc. Boston), pp. 101-104, 1963

[3] M.M. Menon, G.J. Laughon, et al. "Pumping characteristics of a cryopump with $\mathrm{Ar}$ sorbent in $\mathrm{He}$ and in $\mathrm{D}_{2} / \mathrm{He}$ mixture," J. Vac. Sci. Technol. A 13, pp. 551-555, 1995.

[4] J. Kim, K.M. Schaubel, and A.P. Colleraine, "Helium pumping by argon frosting on $4.5 \mathrm{~K}$ surface," J. Vac. Sci. Technol. A 8 , p. 3084, 1990.

[5] J. Kamperschroer, et al., "Cryosorption of helium on argon frost in TFTR neutral beamlines," J. Vac. Sci. Technol. A 8, p. $3079,1990$. 